\title{
EQUILÍBRIO DE FASES PARA O SISTEMA EUGENOL + DICLOROMETANO + DIÓXIDO DE CARBONO EM ALTAS PRESSÕES
}

\author{
A. M. CEZARO ${ }^{1}$, C. STEFFENS ${ }^{1}$, M. V. TRES ${ }^{2}$, J. P. BENDER ${ }^{3}$, J. V. OLIVEIRA ${ }^{4}$
}

${ }^{1}$ Departamento de Engenharia de Alimentos, Universidade Regional Integrada - Campus de Erechim, Erechim, Rio Grande do Sul, Brasil.

2 Universidade Federal de Santa Maria, Cachoeira do Sul, Rio Grande do Sul, Brasil.

${ }^{3}$ Universidade Federal da Fronteira Sul, Erechim, Rio Grande do Sul, Brasil.

${ }^{4}$ Departamento de Química e Engenharia de Alimentos, Universidade Federal de Santa Catarina, Florianópolis, Santa Catarina, Brasil.

\begin{abstract}
RESUMO - Os dados de equilíbrio de fases são essenciais na concepção, modelagem e otimização de processos que envolvem a tecnologia supercrítica. Assim, dados experimentais de equilíbrio de fases para o sistema ternário envolvendo dióxido de carbono + diclorometano + eugenol, utilizando a metodologia estática sintética, foram obtidos para diferentes temperaturas $(35,40$, 45 e $50^{\circ} \mathrm{C}$ ). A fração molar de $\mathrm{CO}_{2}$ adotada variou de 0,3341 a 0,9797 para a razão eugenol:diclorometano (1:1). Transições de fases do tipo líquido-vapor foram visualizadas e observou-se que o aumento da concentração de dióxido de carbono levou a um aumento da pressão de transição em todas as temperaturas estabelecidas.
\end{abstract}

PALAVRAS-CHAVE: Equilíbrio de fases; eugenol; dióxido de carbono; diclorometano.

\section{INTRODUÇÃO}

A utilização de plantas aromáticas, ricas em óleos essenciais, geralmente com ação flavorizante e comprovada ação antibacteriana e antioxidante, pode ser uma alternativa conveniente para a conservação de alimentos. $\mathrm{O}$ cravo é uma das mais importantes especiarias produzidas no Brasil e têm sido muito usado em indústrias de alimentos, cosmética e de produtos farmacêuticos. Seu principal constituinte é o eugenol, um composto aromático muito eficiente, pois apresenta diversos efeitos benéficos com ação antimicrobiana e antioxidante (Silva et al., 2011).

O óleo de cravo apresenta sensibilidade à luz, calor e oxigênio e tem uma vida curta de prateleira em condições inadequadas de armazenamento. Além disso, os extratos de cravo na forma líquida possuem desvantagens em portabilidade e viabilidade comercial como um antioxidante. Dessa forma a busca por proteção e facilidade de manuseio de extratos na forma 
de encapsulados torna-se muito atraente, pois preserva as propriedades biativas destes compostos (Chatterjee \& Bhattacharjee, 2013).

Os dados de equilíbrio de fases são essenciais na concepção, modelagem e otimização de processos que envolvem a tecnologia supercrítica. Este comportamento de fase formado por extratos de produtos naturais e solventes desempenha um papel crucial para elucidar o mecanismo de precipitação envolvida na formação de partículas. Também auxilia na determinação das condições de funcionamento mais satisfatórias para os processos de precipitação e encapsulamento (Benelli et al., 2014).

Nesse sentido o objetivo deste trabalho foi obter dados de equilíbrio de fases envolvendo o sistema ternário dióxido de carbono + diclorometano + eugenol, adquirindo informações sobre o comportamento do eugenol em altas pressões e buscando referências para um estudo futuro de precipitação e encapsulamento do mesmo.

\section{MATERIAL E MÉTODOS}

Para a realização deste trabalho foram utilizados dióxido de carbono (White Martins S.A., pureza de 99,8\%), diclorometano (Synth, pureza de 99,5\%) e eugenol (Sigma Aldrich, pureza de 99\%). A figura 1 apresenta o diagrama esquemático do aparato experimental utilizado neste trabalho.

A finalidade do equilíbrio de fases consiste em fixar uma determinada quantidade de massa do sistema desejado em uma dada temperatura e variar a pressão, até que se encontre a pressão de transição. Nesse caso, pela metodologia sintética estática empregada, deve-se conhecer a composição global do sistema em estudo.

Após a montagem da célula de equilíbrio, são adicionados eugenol e diclorometano com a ajuda de uma seringa descartável, a fim de manter uma determinada proporção de solvente e óleo dentro dela. Conectada à unidade, é adicionado então o dióxido de carbono, através de uma bomba de seringa e o sistema é mantido sob agitação dentro da célula, com a ajuda de um agitador magnético até sua completa homogeneização. Quando a temperatura estiver estável, a pressão é variada lentamente, pela bomba de seringa, até que se observe a transição de fase pela janela de safira.

Para isso, foi estabelecida uma quantidade de dióxido de carbono, nas temperaturas de $35,40,45$ e $50^{\circ} \mathrm{C}$. Além do mais, uma quantidade de eugenol e diclorometano foi fixada de tal forma que a fração molar se mantivesse em 1:1 (eugenol:diclorometano) e as frações molares de $\mathrm{CO}_{2}$ variaram de 0,3341 a 0,9797 .

Figura 1 - Diagrama esquemático do aparato experimental: (A) do cilindro de gás; (B) bomba de seringa; (C) célula de equilíbrio; (D) janela de safira; (E) agitador magnético; (F) fonte de luz; (G) Transdutor de pressão; (H) fonte de energia; (I) indicador de pressão; (J e K) válvula de alimentação; (L e M) válvulas de esfera; $(\mathrm{N})$ da válvula de pressurização da célula; (O) alívio válvula; $(\mathrm{P})$ válvula de retenção; $(\mathrm{Q})$ termopar; e (R) temperatura (Dalmolin, 2013). 


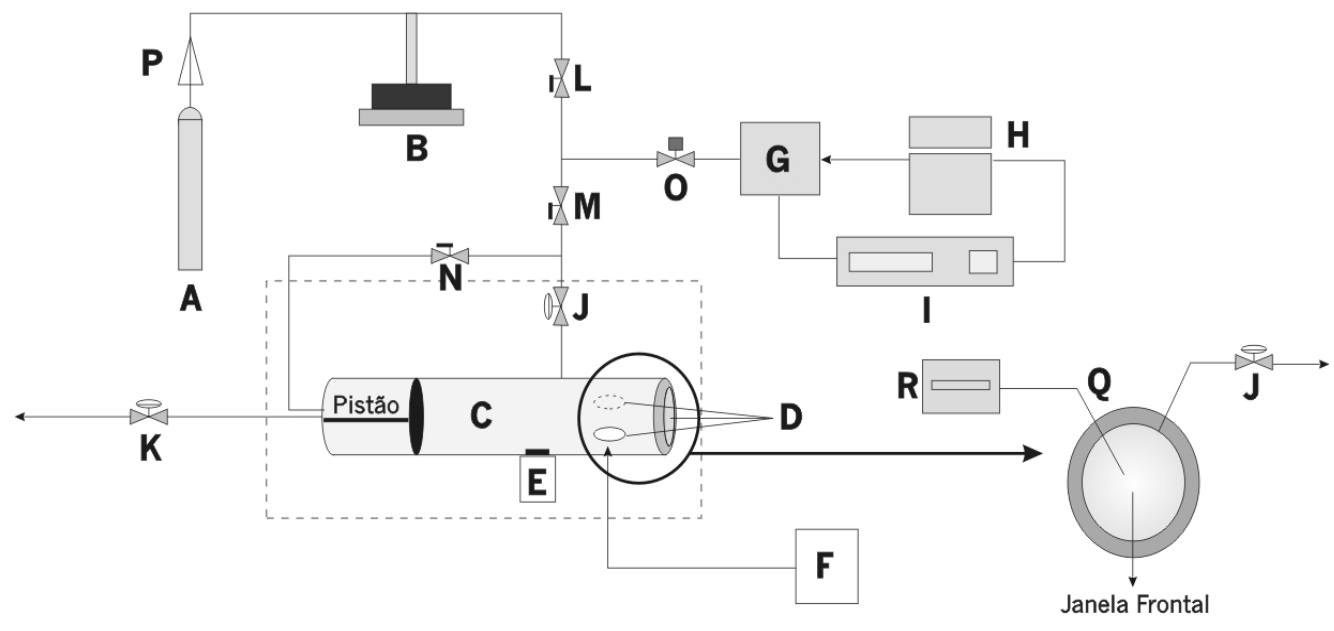

\section{RESULTADOS E DISCUSSÃO}

Os resultados experimentais encontrados nas diferentes temperaturas são apresentados nas Figuras 2 e 3.

Com o incremento da temperatura, há um aumento das pressões de transição, que são afetadas pela composição do sistema. Além disso, um aumento da temperatura acarreta na necessidade de uma maior pressão para que o sistema torne-se totalmente miscível. O ponto crítico da mistura caracteriza-se pela maior pressão de transição encontrada, que variou de 86 bar até 124 bar, dependendo da temperatura empregada (Figura 2). As transições de fases observadas foram do tipo líquido-vapor (ponto de bolha - PB) e (ponto de orvalho - PO), sendo que o aumento da temperatura ocasionou no aumento da pressão de transição, que também é afetada pela composição do sistema (Figura 3).

Comparando os dados experimentais obtidos com os apresentados na literatura, pode-se afirmar que os mesmos encontram-se dentro do esperado. Souza et al. (2004) investigou o sistema binário óleo de cravo + dióxido de carbono e constatou a mesma tendência de comportamento, onde a elevação da temperatura acarreta em uma maior pressão de transição até atingir o ponto crítico e, após isso, elas diminuem. Porém, estas pressões são maiores que as encontradas no sistema ternário estudado. Isto se deve ao fato do diclorometano aumentar a solubilidade do óleo no $\mathrm{CO}_{2}$ e baixar as pressões de transição.

Quando os valores do sistema ternário eugenol + dicloromentano + dióxido de carbono são relacionados com o sistema binário diclorometano + dióxido de carbono, como relatado por Corazza et al. (2003) e Tsivintzelis et al. (2004), acontece o contrário, pois percebe-se que há uma elevação nas pressões de transição quando se adiciona o eugenol. Isso acontece porque a solubilidade do sistema diminui e é necessário maiores pressões para que a transição de fase aconteça. 


\section{Congresso Brasileiro de Engenharia Química em Iniciação Científica Unicamp - Campinas - SP 19 a 22 de julho de 2015}

Figura 2 - Diagrama pressão-composição nas temperaturas 35 (a), 40 (b), 45 (c) e $50^{\circ} \mathrm{C}$ (d).

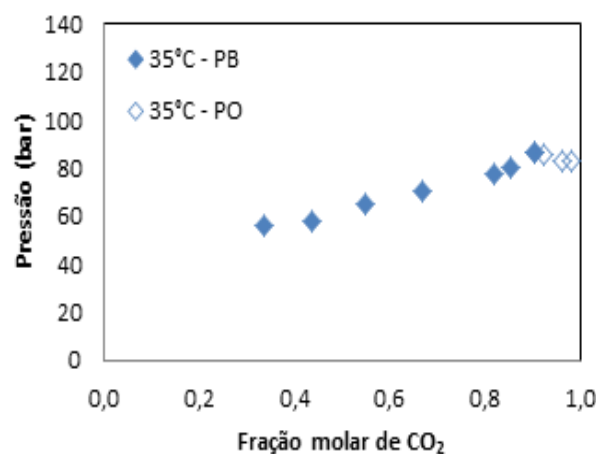

(a)

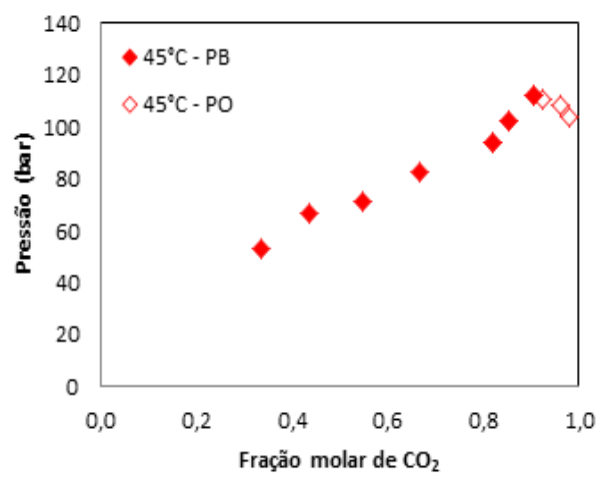

(c)

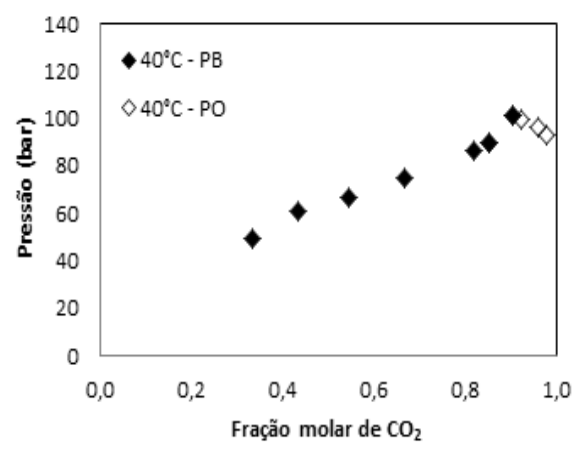

(b)

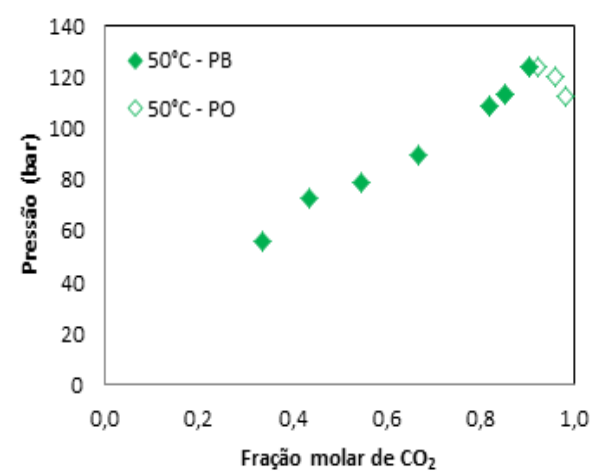

(d)

Figura 3 - Diagrama pressão-composição comparando todas as temperaturas.

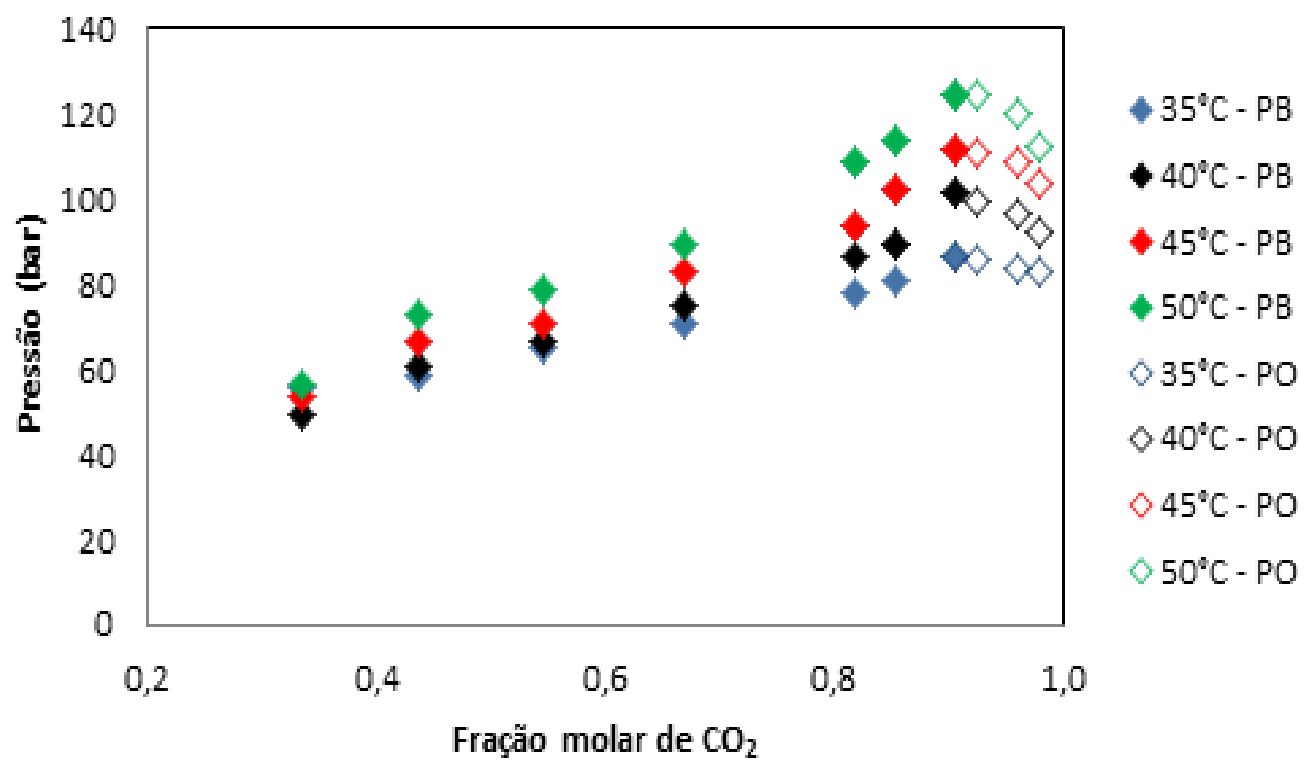




\section{CONCLUSÃO}

O grande interesse despertado pela utilização da tecnologia que envolve a precipitação e encapsulamento de micropartículas, em especial do eugenol, aliado à escassez de estudos sobre o comportamento de fases do meio reacional onde ocorrem tais transformações motivou o presente trabalho.

Resultados experimentais para o sistema contendo dióxido de carbono + diclorometano + eugenol nas temperaturas de $35,40,45$ a $50^{\circ} \mathrm{C}$, com pressões de transição de até 124 bar foram apresentados neste estudo. A fração molar de $\mathrm{CO}_{2}$ variou entre $0,3341 \mathrm{a}$ 0,9797 e a razão molar eugenol:diclorometano foi fixada em 1:1.

As transições de fases observadas foram do tipo líquido-vapor (ponto de bolha - PB e ponto de orvalho - PO), sendo que o aumento da temperatura ocasionou o aumento da pressão de transição, que também é afetada pela composição do sistema. Portanto, estas informações são relevantes quando se leva em consideração o desenvolvimento de tecnologias com fluidos supercríticos em altas pressões, em particular, a fabricação de micro e nano partículas de eugenol.

\section{REFERÊNCIAS BIBLIOGRÁFICAS}

BENELLI, P.; COMIMA, S. R. R.; OLIVEIRA, J.V.; PEDROSA, R.C.; FERREIRA, S.R.S. Phase equilibrium data of guaçatonga (Casearia sylvestris) extract + ethanol $+\mathrm{CO}_{2}$ system and encapsulation using a supercritical anti-solvent process. The Journal of Supercritical Fluids, 2014.

CHATTERJEE, D.; BHATTACHARJEE, P. Comparative evaluation of the antioxidant efficacy of encapsulated and un-encapsulated eugenol-rich clove extracts in soybean oil: Shelf-life and frying stability of soybean oil. Journal of Food Engineering, v. 117, p. 545-550, 2013.

CORAZZA, M. L.; FILHO, L. C.; ANTUNES, O. A. C.; DARIVA, C. High Pressure Phase Equilibria of the Related Substances in the Limonene Oxidation in Supercritical $\mathrm{CO}_{2}$. Journal Chemical. Engineering Data, v. 48, p. 354-358.

DALMOLIN, I. A. Uso de sementes de uva, um resíduo da agroindústria vinícola, empregando tecnologias supercríticas. Tese, Universidade Estadual de Campinas, Faculdade De Engenharia de Alimentos, Campinas/SP, 2013.

SILVA, T.C.; OLIVEIRA, J. R.; SOUZA, S.J.O. Extração de Eugenol a Partir do Cravo da índia e Produção de Sabonetes Aromatizados. Revista Crase edu, v. 01, n. 01, 2011.

SOUZA, A. T.; CORAZZA, M. L.; FILHO, L. C.; GUIRARDELLO, R.; MEIRELES, M. A. A. Phase Equilibrium Measurements for the System Clove (Eugenia caryophyllus) Oil $+\mathrm{CO}_{2}$. Journal. Chemical. Engineering Data, v.49, p. 352-356, 2004. 
TSIVINTZELIS, I.; MISSOPOLINOU, D.; KALOGIANNIS, K.; PANAYIOTOU, C. Phase compositions and saturated densities for the binary systems of carbon dioxide with ethanol and dichloromethane. Fluid Phase Equilibria, v.224, p. 89-96, 2004. 